\title{
Terminologia aplicada à produção científica sobre gestão ambiental: diretrizes à elaboração de um microtesauro
}

Paulo Cesar Chagas Maia

\begin{abstract}
Mestre em Gestão de Recursos Naturais e Desenvolvimento Local na Amazônia NUMA/UFPA. Professor da Universidade Paulista Polo/Belém. Bibliotecário gerente da SEMAS/PA.
\end{abstract}

Mário Vasconcellos Sobrinho

Doutor em Estudos do Desenvolvimento Centre for Development Studies, University of Wales Swansea (Reino Unido). Pesquisador e professor da Universidade da Amazônia. Coordenador do Programa de Pós-Graduação em Gestão de Recursos Naturais e Desenvolvimento Local na Amazônia (PPGEDAM) NUMA/UFPA.

Marise Teles Condurú

Doutora em Ciências do Desenvolvimento
SocioAmbiental NAEA/UFPA. Professora da
Faculdade de Biblioteconomia da UFPA.
Bibliotecária do Núcleo do Meio Ambiente
NUMA/UFPA.

http://dx.doi.org/10.1590/1981-5344/2610

O artigo traça um perfil do debate sobre gestão ambiental na Amazônia à luz das terminologias utilizadas na produção científica dos Programas de Pós-Graduação (PPGs) autorizados pela Coordenadoria de Aperfeiçoamento do Ensino Superior (CAPES) na região, tomando como referência as áreas temáticas Interdisciplinar e Ciências Ambientais. Especificamente, o artigo apresenta um exemplo dentre os principais termos e conceitos utilizados na construção do conhecimento regional por vias das pesquisas de pós-graduação stricto sensu na Amazônia. O arcabouço teórico da pesquisa é alicerçado nas literaturas de gestão ambiental, terminologia, linguagem documentária e tesauro. Metodologicamente, o trabalho segue uma abordagem qualitativa com pesquisa em fonte de papel, cujos dados foram obtidos por meio da uma análise de 332 dissertações de mestrado e 43 teses de doutorado. No 
exame documental utilizou-se de um formulário terminológico com a finalidade de coleta, extração, padronização e análise dos termos ambientais (conceitos) provenientes das produções científicas. A apreciação terminológica permitiu organizar e sistematizar os termos e conceitos utilizados por meio da elaboração de um microtesauro. A construção desse microtesauro com suas relações terminológicas e especificidades em gestão ambiental, contribui para a recuperação da informação ambiental e seu uso adequado na gestão do conhecimento na temática em questão.

Palavras-chave: Terminologia ambiental; Linguagem documentária; Tesauro; Gestão ambiental.

\section{Terminology applied to scientific literature on environmental management: guidelines for a micro- thesaurus building}

The article provides an overview about the debate on environmental management in the Amazon in the light of the terminology used in the scientific production of the Postgraduate Programs (PPGs) authorized by the Federal agency called CAPES. It takes as reference the Interdisciplinary and Environmental Science thematic areas. Particularly, the article shows an example of the key terms and concepts used in the construction of the regional knowledge from the Postgraduate researches in Amazon. The theoretical study framework is grounded in the literature on environmental management, terminology, indexing language and thesaurus. Methodologically, the work follows a qualitative method using paper source. The data were collected by the analysis of 332 master dissertations and 43 PhD theses. It was used a terminological form to deal with the documents and then to collect, extract and to standard the environmental terms (concepts) used in the scientific production of the PPGs. The assessed terminology allows to organize and systematize the terms and concepts used, thus building a micro-thesaurus. The construction of this micro-thesaurus with its terminological relationships and environmental management specificities contributes to recover environmental information and also for its proper use in the knowledge management. 
Keywords: Environmental terminology; Documentary language; thesaurus; Environmental management.

Recebido em 06.11.2015 Aceito em 03.02.2017

\section{Introdução}

A produção dos trabalhos científicos tem aumentado consideravelmente nos últimos anos principalmente no que diz respeito à temática da gestão ambiental. Esse tema tem despertado o interesse de pesquisadores em formação (discentes de mestrado e doutorado) desde os anos de 1990 quando aumentaram as discussões sobre o conceito de desenvolvimento sustentável e as possibilidades de sua aplicabilidade.

No contexto do debate sobre desenvolvimento sustentável, as pesquisas em gestão ambiental ampliaram-se principalmente nos cursos dos Programas Pós-Graduação (PPGs).

A produção desse conhecimento é gerada nos PPGs stricto sensu de mestrado e doutorado, tanto acadêmico como profissional. De fato, os PPGs stricto sensu têm sido responsáveis por um volume da construção do conhecimento científico, pois têm como principal objetivo a formação de pesquisadores - mestres e doutores - que se dedicaram a esse fim (MOOM, 2009).

Entretanto, essa produção científica se dá por meio da elaboração, socialização e disponibilização de teses e dissertações. Segundo Campello (2000, p.124), esses documentos são originados dos cursos de pósgraduação, visando principalmente a capacitação de professores para o ensino superior, além de formar pesquisadores e profissionais de alta qualificação em vários níveis. Elas são consideradas um tipo de Literatura Cinzenta ${ }^{1}$ por não contar com um sistema de publicação e distribuição comercial que permita um acesso maior ao novo conteúdo produzido. Todavia, esses documentos gerados no âmbito dos PPGs e contribuem significativamente para (re)definição de conceitos e termos em diversas áreas do conhecimento, dentre as quais o da gestão ambiental.

Como consequência, novas terminologias têm surgido das dissertações e teses o que tem requerido uma padronização das terminologias ligadas às questões ambientais. A principal tarefa da terminologia aplicada é transformar às unidades da língua natural e da comunicação especializada e propor a representação de conceitos e sistemas de conceitos por meio de termos (LARA, 2005).

Van Der Laan (2002), Botelho (2008), Cervantes (2009) e Vargas (2010) mostram que a elaboração dos tesauros facilita o processo de padronização, organização e recuperação da informação em determinada

\footnotetext{
${ }^{1}$ Literatura Cinzenta, segundo Campello (2000), é um conjunto de documentos que são produzidos em todos os níveis de governo, nas áreas acadêmicas, do comércio e da indústria nos formatos impresso e eletrônico, mas que não é controlada por editores comerciais, tendo como exemplo as publicações comerciais, as dissertações, as teses e a literatura originada de encontros científicos, como os anais de congresso.
} 
especialidade. Em suas concepções, esse instrumento da linguagem documentária e terminológica é essencial para recuperação e representação da informação.

O presente artigo analisa as terminologias ambientais utilizadas na produção científica dos Programas de Pós-Graduação (PPGs) da Amazônia brasileira das áreas temáticas Interdisciplinar e Ciências Ambientais por meio da análise documental e de conteúdo das teses e dissertações. Traçam-se diretrizes para elaboração de um microtesauro terminológico no campo da gestão ambiental.

As diretrizes para a criação do microtesauro como instrumento terminográfico apresentam conceitos a cada descritor ou termo coletado das terminologias em gestão ambiental identificadas na produção científica dos PPGs. Essas são apresentadas na forma da relação de conceitos como instrumento para normalizar a linguagem desta área específica, possibilitando, assim, o entendimento da sua estrutura conceitual.

O texto está estruturado em seis seções contando com esta introdução e considerações finais. Na segunda seção, tem-se uma abordagem teórica sobre a terminologia e a linguagem documentária, focando em um instrumento terminográfico, no caso o tesauro. A terceira seção destaca os aspectos teóricos do conceito gestão ambiental. A quarta seção apresenta os procedimentos metodológicos do artigo, enfatizandose o tipo de pesquisa e o instrumento de coleta de dados. A quinta seção faz uma análise das terminologias utilizadas na produção científica dos PPGs, que teve como resultado final a elaboração de um microtesauro em gestão ambiental.

\section{Entendendo a relação entre terminologia e linguagem documentária}

\subsection{A terminologia}

Na segunda metade do século $X X$, surge um campo de estudos dedicado à Terminologia em uma tentativa de organizar as linguagens e escapar da polissemia e das ambiguidades próprias da linguagem natural. Dessa maneira, por descreverem conteúdos específicos, as terminologias emergem com o objetivo de alcançar a univocidade e a precisão conceitual (FINATTO; KRIEGER, 2004).

Na abordagem de Cabré (1995, p. 4), o objetivo principal da Terminologia é:

a padronização, no sentido de redução a um só tipo de modelo, dos termos típicos de um domínio especializado preciso com a finalidade de fixar as unidades terminológicas com formas normalizadas, estabelecendo os modos de referência e separando as demais variantes para denominar o mesmo conceito e não se limitar a estabelecer a denominação de uma área determinada dentro de um objetivo informativo. 
O objeto da Terminologia é a unidade terminológica - o termo - nos seus aspectos linguísticos, cognitivos e pragmáticos. Os termos constituem um subconjunto de signos linguísticos relativos a uma área conceitual e utilizados na comunicação especializada. A sua principal tarefa é a de observar as unidades da língua natural e da comunicação especializada além de propor a representação de conceitos e sistemas de conceitos através de termos. (LARA, 2005).

Para Sager $(1990)^{2}$ apud Pontes (1997, p. 45), são três as delimitações da noção de terminologia:

(1) a terminologia entendida como o sistema conceptual e de designações de alguma especialidade técnica e científica, isto é, como um conjunto de termos técnicos ou científicos. Neste caso, as terminologias podem apresentar-se na forma de: dicionários terminológicos, glossários e tesauros;

(2) a terminologia entendida como o conjunto de métodos e práticas utilizadas para coleta, descrição, processamento e apresentação de termos;

(3) a terminologia entendida como o conjunto de premissas, argumentos e conclusões requeridos para esclarecer os relacionamentos entre conceitos e termos, o que é fundamental para oferecer coerência à atividade terminológica.

Neste artigo, foi adotada a concepção de terminologia aplicada, também conhecida como terminografia. Essa compreende a elaboração dos instrumentos terminográficos, tais como os tesauros, glossários, dicionários, dentre outros.

O papel da terminologia aplicada é organizar e divulgar os termos técnico-científicos como forma de favorecer a comunicação especializada, por meio de produtos e instrumentos terminológicos. A sua principal característica é ser normalizadora uma vez que busca estabelecer a padronização terminológica e analisa o funcionamento dos termos com vistas a seu registro em instrumentos de referência especializada (FINATTO; KRIEGER, 2004).

A terminologia aplicada nesse contexto padroniza, organiza e sistematiza as informações ambientais produzidas na pesquisa científica. Como dito na introdução, a produção científica ambiental, por meio da elaboração de teses e dissertações, é responsável pelo surgimento de uma diversidade de termos e conceitos ambientais que podem ser sistematizados e organizados por meio do tesauro.

\footnotetext{
${ }^{2}$ SAGER, J. C. A pratical course in processing. [s.I.]: Johm Benjamim; Publishing Company, 1990. p. 42-44.
} 


\subsection{As linguagens documentárias}

A denominação linguagem documentária refere-se ao conjunto dos diferentes tipos de instrumentos especializados no tratamento de informação bibliográfica (sistemas de classificação e tesauros). Para Cintra et al. (2002), a linguagem documentária é um conjunto de termos provindos ou não de regras sintáticas utilizadas para representar conteúdos de documentos técnico-científicos com intuito de classificação ou busca retrospectiva de informações. Nessa mesma direção, Dodebei (2002) mostra que essas linguagens são instrumentos da representação da informação para indexação ${ }^{3}$, armazenamento e recuperação da informação.

Sendo assim, a linguagem documentária vem a ser um instrumento que se destina a estabelecer a ligação entre a linguagem construída para o tratamento dos conteúdos informacionais e a linguagem utilizada pelo usuário para a recuperação dos conteúdos no âmbito de um sistema de recuperação da informação (LARA, 2004).

As linguagens documentárias apresentam os seus termos ordenados alfabeticamente dentro de uma estrutura hierárquica de acordo com as características de cada instrumento. O tesauro é um exemplo representativo dessa estrutura. Lara (2004) identifica diferentes tipos de instrumentos especializados no tratamento dos conteúdos informacionais, citando os tesauros como exemplo.

No Quadro 1, é apresentada a representação da informação, segundo Dodebei (2002), em que o tesauro é um instrumento da Linguagem Documentária, sendo elaborado a partir de determinada área do conhecimento.

Quadro 1 - Quadro da representação documentária

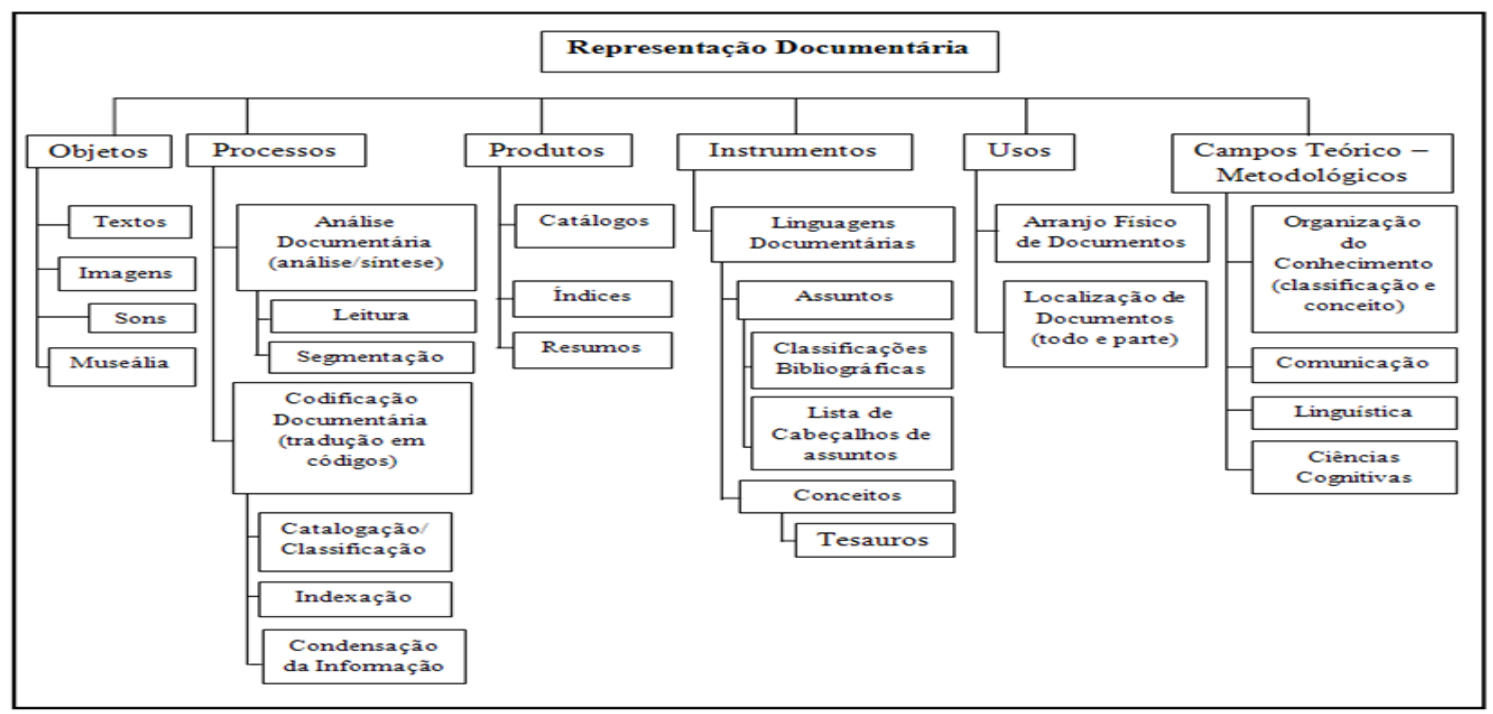

Fonte: DODEBEI (2002, p.43).

\footnotetext{
${ }^{3}$ Conforme a NBR 12676 - Métodos para análise de documentos, indexação é o processo de determinação de assuntos de um documento e a sua posterior tradução para uma linguagem de indexação (ASSOCIAÇÃO BRASILEIRA DE NORMAS TÉCNICAS, 1992).
} 
No mesmo sentido, Cintra et al. (2002) afirma que essas linguagens correspondem a sistemas de símbolos destinados a traduzir os conteúdos dos documentos. Elas são linguagens construídas para representar, de maneira sintética, as informações contidas nos textos acadêmicos. Uma das funções dessas linguagens é controlar e padronizar os assuntos, função cumprida principalmente pela elaboração dos tesauros.

\subsection{0 tesauro}

A terminologia tem um caráter interdisciplinar e devido à sua função de representar serve à documentação por meio da elaboração de tesauros. É um elemento importante de representação do conteúdo dos documentos e de encontro entre os mesmos, uma vez que a capacidade de uma linguagem documentária em recuperar as informações é intimamente dependente de sua capacidade de referir e representar adequadamente (CABRÉ, 1995).

E para que essa capacidade de referir se concretize deve ser realizada a construção de linguagens documentárias com base na terminologia da área, pois a mesma remete a sistemas de significação da área, constituindo, portanto, base legal para a construção das linguagens documentárias.

Percebe-se a relação entre as áreas após o entendimento das linguagens documentárias e da terminologia. Neste artigo, é abordada a utilização e elaboração do tesauro terminológico como um instrumento de organização, padronização e sistematização da informação.

Segundo Sales (2008), a importância dos tesauros como instrumento da linguagem documentária e terminológica é caracterizada pela especificidade e complexidade existente no relacionamento entre os termos que comunicam o conhecimento especializado.

O tesauro tem como objetivo diminuir as barreiras da representação e recuperação da informação e, dessa forma, minimizar os ruídos e as falhas conceituais da comunicação técnica e científica. Adicionalmente, tem como finalidade o controle terminológico, a normalização, unificação e padronização dos termos em determinada área do conhecimento humano.

Para Currás (1995, p. 34), o tesauro foi inicialmente "adotado na área de documentação, associado à forma de organização do vocabulário de indexação/recuperação". No ambiente organizacional, pode ser utilizado na representação dos assuntos, documentos e nas buscas informacionais que subsidiam a tomada de decisão. Na concepção dessa mesma autora, tesauro é definido como "uma linguagem especializada, normalizada, pós-coordenada, usada com fins documentários cujos elementos linguísticos que o compõe (termos simples ou compostos) encontram-se relacionados entre si sintática e semanticamente" (CURRÁS, 1995).

É necessário que por linguagem especializada entenda-se como aquela que atua em um domínio restrito; por normalizada, compreenda-se como uma linguagem controlada; as unidades linguísticas como termos e, finalmente, por pós-coordenada aquelas cujos termos são combinados no 
momento de seu uso em oposição às linguagens pré-coordenadas em que os termos que designam assuntos complexos se coordenam previamente à sua utilização conceitual (MOREIRA; ALVARENGA; OLIVEIRA, 2004).

$\mathrm{Na}$ concepção das diretrizes para a construção de tesauros descritas do padrão norte-americano, tesauros é definido como:

um vocabulário controlado organizado em uma ordem preestabelecida e estruturado de modo a que os relacionamentos de equivalência, de homografia, de hierarquia e de associação entre termos sejam indicados claramente e identificados por indicadores de relacionamento padronizados empregados reciprocamente (AMERICAN, 2003 ${ }^{4}$ apud SALES; CAFÉ, 2009, p. 109).

Jesus (2002) afirma que o principal objetivo do tesauro é dar assistência ao usuário (pesquisador ou indexador) de maneira que ele consiga encontrar o termo que represente um determinado significado para o que se procura, ou seja, o usuário no momento da busca, com a ajuda do tesauro, poderá identificar termos alternativos, permitindo descrever a informação contida no documento de maneira mais adequada.

Há uma série de condições a serem cumpridas por um tesauro, como por exemplo: deve ser uma linguagem especializada, deve permitir a introdução ou supressão de termos para manter sua atualidade e deve servir de conversor da linguagem natural dos documentos, ambígua e livre, para uma linguagem concreta, normalizada e apta a controlar a informação contida nos documentos (CURRÁS, 1995).

$\mathrm{Na}$ abordagem de Foskett $(1973)^{5}$ apud Maculan e Lima (2014, p. 185), o tesauro possui diferentes funções, tais como: controle de sinônimos e quase sinônimos, a promoção de melhorias na busca do usuário por meio dos termos relacionados; a redução do tempo e do aumento da eficiência nas tarefas de indexação e recuperações de informações.

Como linguagem terminológica, o tesauro tem como uma de suas principais características as relações entre os termos segundo indicações estabelecidas por seu próprio significado, de modo que uns conduzam a outros (CURRÁS, 1995).

De acordo com Currás (1995) e Van der Lan (2002), as relações que se estabelecem em um tesauro são:

a) relações conceituais: estabelecidas entre os conceitos representados pelos temos no tesauro, sendo subdividas em: hierárquicas - baseadas no grau de semelhança entre os indivíduos, estabelecendo-se uma relação de subordinação e superordenação. Há um termo superior, geral ou genérico, representado por TG e o termo específico com menor conteúdo e significado, representado por TE; associativas - as relações

\footnotetext{
${ }^{4}$ AMERICAN NATIONAL STANDARDS INSTITUTE. Guidelines for the construction, format and management of monoligual thesauri. Berthesda, 2003.

${ }^{5}$ FOSKETT, A. C. A abordagem temática da informação. São Paulo: Polígono, 1973.
} 
são por coordenação, podendo ser também por encadeamento, causa e efeito ou sequência que é o termo relacionado representado por TR;

b) relações de equivalência: estabelecidas entre termos que representam os conceitos em um tesauro, podendo haver um termo preferido e outro não preferido funcionando como seu sinônimo ou quase sinônimo. São representados por USE e UP (usado por).

Segundo Lorenzon (2011), já existem tesauros que estão vindos com a nota de escopo ou nota explicativa presentes nas suas relações. As notas de escopo são usadas no tesauro para restringir ou expandir o uso de um descritor, podendo distinguir descritores que possuem o mesmo significado na linguagem natural ou provendo direção para uso de outro termo no processo de indexação e para a recuperação da informação. São representadas pela sigla NE.

Os termos e seus relacionamentos podem ser apresentados de várias maneiras em um tesauro. Segundo Instituto Brasileiro de Informação em Ciência e Tecnologia (IBICT, 1984), Derek (1993) e Currás (1995), existem três métodos básicos de apresentação atualmente em uso: a) apresentação alfabética com notas explicativas e relações entre os termos indicadas em cada um deles; b) apresentação sistemática, auxiliada por um índice alfabético; c) apresentação gráfica com uma seção alfabética.

\section{Refletindo sobre a gestão ambiental}

O termo gestão tem a origem na Administração. Está diretamente relacionado aos quatro pilares que sustentam a tomada de decisão e auxiliam o desenvolvimento de processos de forma geral: planejamento, organização, direção e controle.

Ao ser iniciada a discussão sobre a expressão "gestão ambiental", é importante entender o significado dos termos "gestão" e "ambiental'. A concepção de Phillipi Jr., Roméro e Bruna (2004, p. 700) define esses termos da seguinte maneira:

o significado etimológico dos dois vocábulos - gestão e ambiental - tem suas raízes na língua latina. Gestão originouse de gestioni que exprime o ato de gerir. Gerir é um verbo inusitado no linguajar e cada dia, cujo significado é ter gerência sobre administrar, reger e dirigir. Enquanto, o vocábulo ambiental também tem origem na língua latina. É o adjetivo aplicado para referir-se às coisas do ambiente; tanto ambiente construído, quanto ambiente natural.

Com base nesses entendimentos, a gestão ambiental é o ato de gerir o ambiente, isto é, o ato de administrar, dirigir ou reger as partes constitutivas do meio ambiente (PHILLIPI JR.; ROMÉRO; BRUNA, 2004). 


\subsection{Conceituando e caracterizando a gestão ambiental}

Como forma de compreender o que vem a ser a temática gestão ambiental se considera necessário compreender o seu significado. Philippi Jr., Roméro e Bruna (2004, p. 700) a definem como o ato de administrar, dirigir ou reger os ecossistemas naturais e sociais em que se insere o homem, individual e socialmente, num processo de interação entre as atividades que exerce, buscando a preservação dos recursos naturais e das características essenciais do entorno de acordo com padrões de qualidade. O objetivo último é estabelecer, recuperar ou manter o equilíbrio entre a natureza e o homem.

$\mathrm{Na}$ busca pela minimização dos conflitos da sociedade atual, a gestão ambiental, de acordo com Machado et al. (2002), é definida como uma atividade voltada para a formulação de princípios e diretrizes, estruturação de sistemas gerenciais e tomada de decisões, tendo por objetivo final promover de forma coordenada o uso, a proteção, conservação e o monitoramento dos recursos naturais e socioeconômicos em um determinado espaço geográfico com vistas ao desenvolvimento sustentável.

Nessa mesma linha teórica, Quintas (2006, p. 30) conceitua gestão ambiental como "processo de mediação de interesses e conflitos entre atores sociais que agem sobre o meio físico natural e construído, objetivando garantir 0 direito ao meio ambiente ecologicamente equilibrado".

Podemos caracterizar que a gestão ambiental busca a condução harmoniosa dos processos dinâmicos e interativos que ocorrem entre os diversos componentes do ambiente natural e antrópico determinados pelo padrão de desenvolvimento almejado pela sociedade. Para que ocorra um processo efetivo de gestão ambiental é necessário um grande conhecimento das dinâmicas que envolvem ambos os tipos de ecossistemas, porque processos humanos que direcionam os aspectos sociais, econômicos e culturais de dada região estão em constante interação com os processos naturais (SEIFFERT, 2011).

A gestão do meio ambiente ou gestão ambiental é, então, o ato de gerir um território por meio de ações políticas e técnicas para o uso e aproveitamento dos recursos naturais, de forma menos predatória possível, para preservar a sócio-bio e cultural diversidade em prol da perenização da espécie humana, da terra, flora, fauna e biota. A gestão ambiental tem como princípio a preservação dos elementos físicos e biológicos fundamentais para a sobrevivência das pessoas e o uso sustentável dos recursos naturais. A gestão ambiental pode ser definida como aquela gestão que é orientada, enquanto finalidade, para as pessoas, embora essas sejam apenas uma das espécies do ambiente natural (VASCONCELLOS SOBRINHO, 2014).

A gestão ambiental é um dos, senão o mais importante, instrumento para o desenvolvimento sustentável, estando, porém, vinculado a normas emanadas do poder público e agências reguladoras (DIAS, 2006). Na visão de Barbieri (2011, p. 19), a gestão do meio ambiente é entendida 
como as diretrizes e as atividades administrativas e operacionais, tais como planejamento, direção, controle e alocação de recursos com o objetivo de obter efeitos positivos sobre o meio ambiente, reduzindo, eliminando ou compensando os danos ou problemas causados pelas ações humanas.

Nesse contexto, Philippi Jr. e Maglio comentam que gestão ambiental é, portanto, um processo político administrativo de responsabilidade do poder constituído destinado a, com a participação social, formular, implementar e avaliar políticas ambientais a partir da cultura, realidade e potencialidades de cada região em conformidade com os princípios do desenvolvimento sustentável. (PHILIPPI JR.; MAGLIO, 2005).

Dessa forma, a gestão ambiental reveste-se de extensão e complexidade e deve ser tratada em seu contexto amplo, não se limitando a aspectos isolados (PHILIPPI JR.; ROMÉRO; BRUNA, 2004).

Logo, a gestão ambiental consiste em uma estrutura, que sob a ótica sistêmica, agrega planejamentos, responsabilidades, práticas, procedimentos e processos a fim de que haja uma mobilização interna e externamente a organização a fim de atingir a qualidade ambiental almejada (TINOCO; KRAEMER, 2008).

Nesse sentido, o objetivo da gestão ambiental é promover o equilíbrio entre os aspectos sociais, econômicos, ambientais e políticos inerentes a existência e ao conjunto de relações humanas, mantendo-se atentos aos normativos emanados do poder público e entidades com poder para emitir normatizações a respeito (DIAS, 2006).

Para Seiffert, (2011, p. 54) a gestão ambiental integra em seu significado as seguintes informações:

a)a política ambiental, que é o conjunto consistente de princípios doutrinários que conformam as aspirações sociais ou governamentais no que concerne a regulamentação ou modificação no uso, controle, proteção e conservação do ambiente;

b)o planejamento ambiental, que é o estudo prospectivo que visa a adequação do uso, controle e proteção do ambiente às aspirações sociais ou governamentais expressas formal ou informalmente em uma política ambiental, através da coordenação, compatibilização, articulação e implantação de projetos de intervenções estruturais e não estruturais;

c) o gerenciamento ambiental, que é um conjunto de ações destinado a regular o uso, controle, proteção e conservação do meio ambiente e a avaliar a conformidade da situação corrente com os princípios doutrinários estabelecidos pela política ambiental. 
A finalidade da gestão ambiental é a busca da harmonia entre o homem - aquele ser social - e seu meio ambiente natural ou construído. Em outras palavras, a gestão ambiental fundamenta a sua razão de ser na conquista de um nível ideal de qualidade de vida para sociedade e todos os seus membros (PHILIPPI JR.; ROMÉRO; BRUNA, 2004).

Após a realização das considerações conceituais sobre terminologias, linguagem e gestão ambiental, parte-se para a explicação dos procedimentos metodológicos que nos levaram à proposição de diretrizes para a construção do microtesauro.

\section{Procedimentos metodológicos para construção do microtesauro}

Para a análise terminológica da área de gestão ambiental desenvolvida neste artigo, foi realizado um estudo exploratório no portal (sites) dos Programas de Pós-Graduação (PPG) credenciados pela Coordenação de Aperfeiçoamento de Pessoal de Nível Superior (CAPES) na Região Norte, sendo selecionados os seguintes programas stricto sensu:

a)Área Interdisciplinar: (1) Programas de Pós-Graduação de Gestão dos Recursos Naturais, Desenvolvimento Local na Amazônia (PPGEDAM/NUMA/UFPA), (2) Programas de PósGraduação em Desenvolvimento Sustentável do Trópico Úmido (PPGDSTU/NAEA/UFPA);

b)Ciências Ambientais: (3) Programas de Pós-Graduação em Ciências do Ambiente e Sustentabilidade na Amazônia (PPGCASA/UFAM) e (4) Programas de Pós-Graduação em Ciências Ambientais (PPGCA/UFPA).

Nessa fase da pesquisa, a intenção foi coletar informações pertinentes ao desenvolvimento do estudo, conhecendo as áreas temáticas e linhas de pesquisa dos programas para posterior análise terminológica.

Em razão da abrangência dessas áreas temáticas que a cada ano produzem uma quantidade significativa de trabalhos científicos e, por conseguinte, não sendo possível analisar toda a produção acadêmica existente nos programas, foi realizado um recorte temporal da pesquisa entre os anos de 2009 a 2013, no qual foram produzidas 332 dissertações de mestrado e 43 teses de doutorado.

Metodologicamente, o estudo seguiu uma abordagem qualitativa, com ênfase na análise do conteúdo dos documentos (os significados da terminologia ambiental) e, por conseqüência, o entendimento que expressa à comunicação do autor nas dissertações e teses. Buscou-se fazer as relações dos termos e conceitos ambientais para posterior elaboração de um microtesauro sobre gestão Ambiental.

Para atingir o objetivo proposto, no que diz respeito às técnicas de pesquisa, utilizou-se como instrumento de coleta de dados o diário de 
pesquisa e um formulário terminológico durante as consultas periódicas nas dissertações e teses dos PPGs.

O formulário terminológico foi construído com a finalidade de extração e coleta dos termos e conceitos na área ambiental. Esse instrumento teve uma função importante na coleta, extração, organização e análise das informações, pois através de sua aplicação foi possível realizar uma leitura técnica e aprofundada da produção científica. Analisaram-se as relações entre os termos e conceitos, e identificaram-se as ambiguidades, os conceitos polissêmicos e as novas interpretações da ciência regional ambiental. Para Finatto e Krieger (2004, p. 137), "o formulário terminológico é um instrumento indispensável na organização de repertórios de terminologias e constitui um núcleo de informações a cerca de um termo ou expressão sob estudo". Nessa ficha, constam informações sobre variantes de termos, sinônimos, definições, dentre outros.

O registro dos termos foi realizado após a leitura técnica e identificação dos conceitos e termos no momento da análise do conteúdo dos documentos. Em seguida, foi elaborada uma lista de conceitos em ordem alfabética. Nesse momento, foi construído um quadro terminológico que serviu de base para identificar os conceitos mais usados nos PPGs.

\section{A elaboração do microtesauro em gestão ambiental: um exemplo real}

Para a elaboração do Microtesauro em Gestão Ambiental atentou-se para a necessidade de criação de um instrumento de linguagem documentária conforme Cintra et al. (2002), Jesus (2002) e Lara (2004), no qual se deve estabelecer relação entre a linguagem documentária (tesauros) para o tratamento dos conteúdos informacionais e a linguagem utilizada pelo usuário para a recuperação desses conteúdos.

Dodebei (2002) diz que o tesauro é um instrumento da linguagem documentária que pode ser elaborado a partir de determinada área do conhecimento, o que neste caso é o de gestão ambiental.

O microtesauro em gestão ambiental foi estruturado com termos preferidos e ou não preferidos, organizados em ordem alfabética, sendo os termos selecionados apresentados em letras maiúsculas e em negrito.

A relação conceitual dos termos utilizada nesse microtesauro foi a de forma hierárquica e associativa, sendo a primeira representada pelos termos geral (TG) e específico (TE), enquanto que a associativa apresenta o termo relacionado, representado pela sigla TR. Adotou-se na relação, a nota de escopo ou nota explicativa (NE) para conceituar o descritor escolhido no tesauro de gestão ambiental (LANCASTER, 1987; CURRÁS, 1995 e VAN DER LAN, 2002).

No Quadro 2, é apresentado o modelo utilizado no microtesauro sobre gestão ambiental em que se observa essas relações, tomando como exemplo o termo geral (TG) ou termo maior áreas protegidas.

Para esse termo geral, são adotados os termos específicos (TE) ou áreas específicas: área de proteção ambiental, reserva extrativista, 
unidade de conservação e parque urbano, que indicam que as pesquisas desenvolvidas em áreas protegidas têm sido detalhadas nesses termos individualmente (termos menores) ou também associados.

Em relação ao termo relacionado (TR), tem-se a gestão em unidades de conservação, no qual se pode encontrar a relação de gestão de áreas protegidas, em especial de unidades de conservação. Assim, é uma forma de complementar o tema áreas protegidas de igual maneira que esse no tema gestão de unidades de conservação estará relacionado.

A nota de escopo ou nota explicativa é um conceito do termo geral (descritor) áreas protegidas. Esse conceito é o adotado (extraído) durante a análise terminológica das teses e dissertações dos PPGs.

Quadro 2 - Relações do microtesauro sobre gestão ambiental

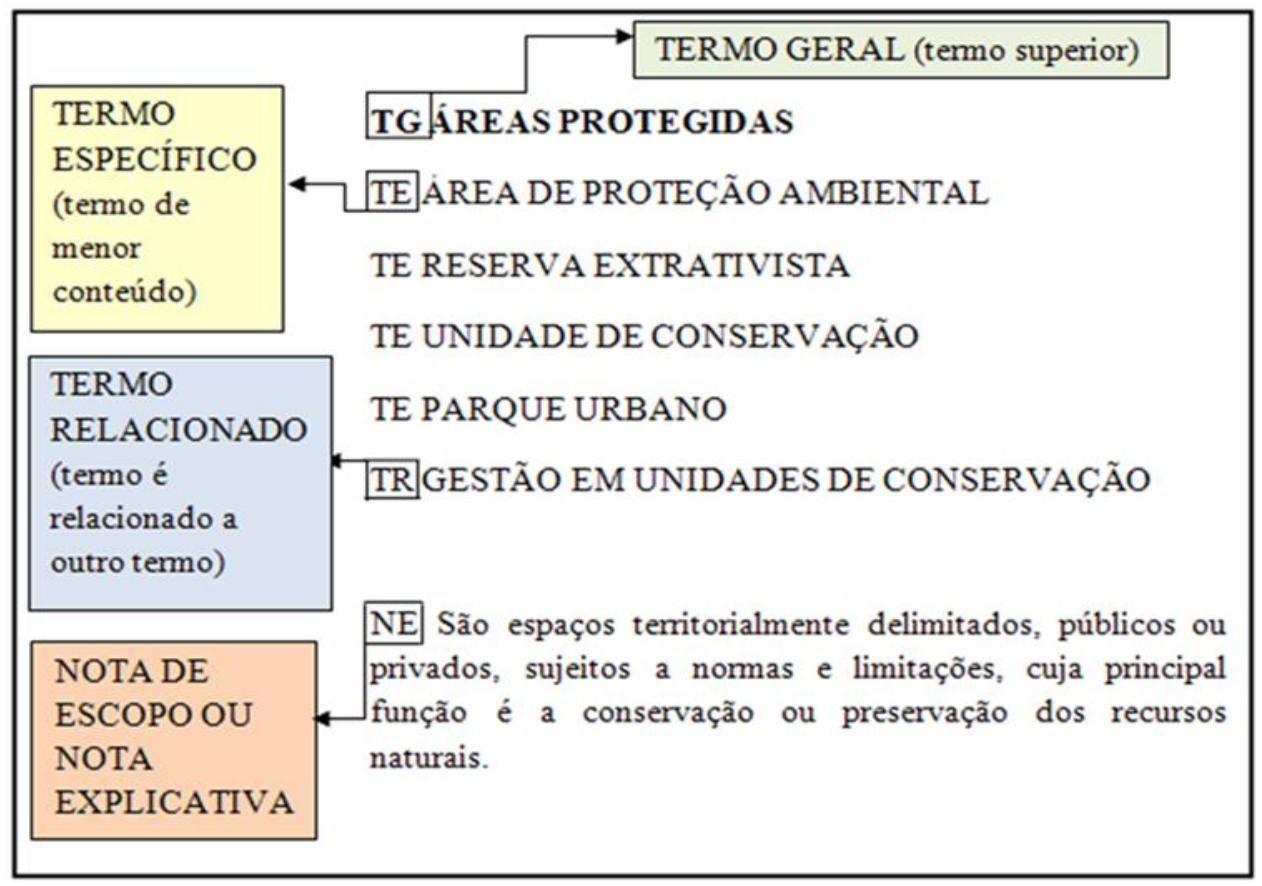

Fonte: Elaborado pelos autores (2014).

Portanto, para o termo geral ou superior áreas protegidas consideram-se 0 uso de diferentes termos específicos que podem representar o conteúdo de documentos, não sendo necessariamente adotados todos eles.

Por outro lado, o termo relacionado gestão de unidades de conservação significa que ao termo escolhido como geral (áreas protegidas) existem outros que de alguma forma tem ligação com ele. Assim, essa relação estabelecida favorece 0 entendimento e a compreensão de cada termo ambiental para o desenvolvimento de pesquisas em gestão ambiental.

Esse exemplo extraído do microtesauro construído permite visualizar o entendimento do termo gestão ambiental conforme definições de 
Barbieri (2011), Machado et al. (2002), Philippi Jr. e Maglio (2005), Philippi Jr., Roméro e Bruna (2004), Quintas (2006), Tinoco e Kraemer (2008) e Vasconcellos Sobrinho (2014). Definições em que se percebe a necessidade de gerir o meio ambiente a fim de manter o equilíbrio da qualidade de vida dos seres que nele se desenvolvem.

No Quadro 3, são apresentadas, como exemplo, algumas relações do microtesauro sobre gestão ambiental com sua estrutura hierárquica, relações com termos ambientais, suas especificidades.

\section{Quadro 3 - Apresentação das relações do microtesauro sobre gestão ambiental}

\begin{tabular}{|c|c|}
\hline $\begin{array}{l}\text { TG DESENVOLVIMENTO LOCAL } \\
\text { TE CAPITAL SOCIAL } \\
\text { TE CADEIA PRODUTIVA } \\
\text { TE DESENVOLVIMENTO COMUNITÁRIO } \\
\text { TE ARRANJO PRODUTIVO LOCAL } \\
\text { TR POLÍTICA DE DESENVOLVIMENTO LOCAL } \\
\text { NE É o desenvolvimento que se caracteriza por ser endógeno, } \\
\text { nasce das forças internas da sociedade; constitui um todo com } \\
\text { dimensões ecológicas, culturais, sociais, econômicas, } \\
\text { institucionais e políticas, sendo que a ação a seu serviço deve } \\
\text { integrar todas essas dimensões. }\end{array}$ & $\begin{array}{l}\text { TG AVALIAÇÃO DE IMPACTO AMBIENTAL } \\
\text { TE PLANO DE AÇÃO AMBIENTAL } \\
\text { TE ESTUDO DE IMPACTO AMBIENTAL } \\
\text { TE RELATÓRIO DE IMAPCTO AMBIENTAL } \\
\text { TR IMPACTO SÓCIO AMBIENTAL } \\
\text { NE É um instrumento de política ambiental formado por } \\
\text { um conjunto de procedimentos capaz de assegurar, desde } \\
\text { o início do processo, que se faça um exame sistemático } \\
\text { dos impactos ambientais de uma ação proposta e de suas } \\
\text { alternativas. }\end{array}$ \\
\hline $\begin{array}{l}\text { TG EDUCAÇÃO AMBIENTAL } \\
\text { TE EDUCAÇÃO PARTICIPATIVA } \\
\text { TE EDUCAÇÃO RURAL } \\
\text { TE EDUCAÇÃO NO CAMPO } \\
\text { TR INDICADORES EDUCACIONAIS } \\
\text { NE É uma proposta de educação que visa a participação dos } \\
\text { cidadãos nas discussões e decisões sobre a questão ambiental. }\end{array}$ & $\begin{array}{l}\text { TG GESTÃO } \\
\text { TE GESTÃO AMBIENTAL } \\
\text { TE GESTÃO DEMOCRATICA } \\
\text { TE GESTÃO PARTICIPATIVA } \\
\text { NE Sob a ótica da administração, está relacionado com o } \\
\text { conjunto de recursos decisórios e a aplicação das } \\
\text { atividades destinadas aos atos de gerir. }\end{array}$ \\
\hline $\begin{array}{l}\text { TG GESTÃO AMBIENTAL } \\
\text { TE PLANO DE MANEJO } \\
\text { TE CONSELHO DELIBERATIVO } \\
\text { TE MONITORAMENTO AMBIENTAL } \\
\text { TE EDUCAÇÃO AMBIENTAL } \\
\text { TE AVALIAÇÃO DE IMPACTO AMBIENTAL } \\
\text { TE LICENCIAMENTO AMBIENTAL } \\
\text { TR GESTÃO EM UNIDADES DE CONSERVAÇÃO } \\
\text { NE É a condução, a direção e o controle pelo governo do uso } \\
\text { dos recursos naturais, através de determinados instrumentos, o } \\
\text { que inclui medidas econômicas, regulamentos e normalização, } \\
\text { investimentos públicos e financiamento, requisitos } \\
\text { interinstitucionais e judiciais. }\end{array}$ & $\begin{array}{l}\text { TG GESTÁO DA ÁGUA } \\
\text { TE ABASTECIMENTO DE ÁGUA } \\
\text { TE ÁGUA } \\
\text { TE SISTEMA DE ABASTECIMENTO DE ÁGUA } \\
\text { NE É concebida através de métodos organizados, cujo } \\
\text { objetivo principal é solucionar problemas concernentes ao } \\
\text { uso e ao controle dos recursos hídricos, atendendo, } \\
\text { dentro de suas limitações econômicas e ambientais e } \\
\text { considerando os princípios de justiça social, à demanda } \\
\text { pela sociedade, a partir das disponibilidades limitadas, } \\
\text { previstas em estudos de investigação e diagnóstico. }\end{array}$ \\
\hline $\begin{array}{l}\text { TG LICENCIAMENTO AMBIENTAL } \\
\text { TE LICENÇA AMBIENTAL } \\
\text { TE LICENÇA PRÉVIA } \\
\text { TE LICENÇA DE INSTALAÇÃO } \\
\text { TE LICENÇA DE OPERAÇÃO } \\
\text { NE Constitui um importante instrumento de gestão do ambiente } \\
\text { na medida em que, por meio dele, a administração pública } \\
\text { busca exercer o necessário controle sobre as atividades } \\
\text { humanas que interferem nas condições ambientais de forma a } \\
\text { compatibilizar o desenvolvimento econômico com preservação } \\
\text { do equilíbrio ecológico. }\end{array}$ & $\begin{array}{l}\text { TG RESERVA EXTRATIVISTA } \\
\text { TE EXTRATIVISMO } \\
\text { TE NEOEXTRATIVISMO } \\
\text { TE FLORESTA } \\
\text { TE RESERVA FLORESTAL } \\
\text { TE RESERVA DE DESENVOLVIMENTO SUSTENTÁVEL } \\
\text { NE É uma Unidade de Conservação (UC) destinada à } \\
\text { exploração autossustentável e conservação dos recursos } \\
\text { naturais renováveis por populações tradicionais } \\
\text { extrativistas. }\end{array}$ \\
\hline
\end{tabular}

Fonte: Elaborado pelos autores (2014).

Percebe-se nessas relações conceituais a importância de se identificar a grande área do conhecimento ambiental e suas especificidades para que haja de fato a apropriação e explicação do conteúdo das pesquisas. Esses descritores (termos autorizados) mostram a relação da gestão ambiental com seus principais instrumentos de gestão 
e suas áreas específicas de atuação, facilitando, assim, o entendimento do conceito selecionado.

Com efeito, a elaboração desse instrumento propicia compreender as relações conceituais em gestão ambiental, tendo como finalidade o controle terminológico, a recuperação da informação e a padronização da informação ambiental.

É oportuno reforçar a necessidade de atualização do tesauro ambiental de forma permanente (constante), ou seja, deve ser uma atividade contínua no campo da terminologia ambiental, devido o surgimento e o registro de ocorrência de novos termos e definições na área da gestão ambiental.

\section{Considerações finais}

A relevância da terminologia para estudos especializados se efetiva no momento que possibilita entender, conhecer e representar seus objetos de estudo e transferir esse conhecimento a outras áreas e contextos e é isso que esse estudo terminológico pretende realizar na temática gestão ambiental.

O conhecimento disseminado em publicações científicas provenientes de Programas de Pós-Graduação stricto sensu na temática da gestão ambiental tem gerado diversos termos e conceitos, os quais, muitas vezes, sem padronização terminológica provocam polissemia e ambiguidade nos significados e definições.

Para evitar que isso ocorra, é importante que estudos especializados efetivos de análise terminológica possibilitem entender, conhecer e representar seus objetos de estudo e transferir esse conhecimento especializado a outras áreas e contextos.

Dessa maneira, neste artigo, apresentou-se um exemplo de análise terminológica realizada a partir das dissertações e teses dos PPGs da Região Norte nas áreas interdisciplinar e ambiental, o que permitiu conhecer as atuais formas de representação do conteúdo desses documentos sobre a temática gestão ambiental. O trabalho completo está descrito em Maia (2015).

O microtesauro em gestão ambiental foi estruturado com termos preferidos e não preferidos, organizados em ordem alfabética. Esse instrumento da linguagem documentária permitiu demonstrar as relações conceituais no âmbito da gestão ambiental com suas grandes áreas e especificidades, tendo como intuito o controle terminológico, a recuperação da informação e a padronização da informação ambiental.

A elaboração do microtesauro terminológico possibilitou identificar os termos próprios do campo da gestão ambiental, fornecer referências para a compreensão de termos e conceitos, organizar e divulgar informações científicas ambientais e constituir-se em um instrumento terminológico para representação e transmissão do conhecimento especializado na temática gestão ambiental, sendo uma importante fonte de informação em meio ambiente. 
O diferencial desse microtesauro cujo exemplo foi descrito neste artigo é que na sua estrutura é apresentada a chamada nota de escopo ou nota explicativa, isto é, informa o conceito do termo escolhido utilizado na temática gestão ambiental, facilitando o entendimento da definição e das relações conceituais e hierárquicas.

Como instrumento de tomada de decisão, o microtesauro de gestão ambiental servirá na busca e recuperação da informação ambiental pelo profissional da informação (bibliotecário) em uma unidade de informação, disponibilizando essa informação para o usuário que precisa desenvolver as suas pesquisas no campo na gestão ambiental e outros temas interdisciplinares.

Por outro lado, no ambiente organizacional, o microtesauro pode ser utilizado para a representação dos assuntos, de documentos e nas buscas informacionais que subsidiam a tomada de decisão, propiciando a padronização e sistematização da informação ambiental assim como o controle terminológico mais eficaz, fortalecendo o campo da gestão ambiental na Região Amazônica.

$\mathrm{Na}$ própria relação do microtesauro consta a definição do termo genérico (descritor) gestão ambiental com suas especificidades identificadas aos principais instrumentos que podem ser usados pelos gestores para tomar decisões como áreas protegidas, plano de manejo, licenciamento ambiental, monitoramento ambiental, educação ambiental e avaliação de impacto ambiental. Entender 0 significado dessas terminologias fortalece a comunicação entre os especialistas na pesquisa ambiental na Amazônia.

Nenhum instrumento da linguagem documentária ou da terminografia é completo, e, por isso, o microtessauro precisa ser monitorado e observado para que a sua autenticidade não deixe de existir, pois a sua credibilidade depende da especificidade selecionada, no caso a gestão ambiental.

Essa pesquisa mostrou que a partir da análise terminológica nos PPGs da Amazônia houve um subsídio no avanço do conhecimento sob gestão ambiental, sobretudo em sua interpretação e aplicação na Região Amazônica, principalmente na produção científica dos programas de pósgraduação na especialidade gestão ambiental que retratam suas contribuições para o avanço no entendimento do conceito.

A análise terminológica que resultou na elaboração do microtesauro em gestão ambiental, além de contribuir como ferramenta de auxílio ao profissional da informação na representação e recuperação da informação para tomada de decisões, auxilia, também, o usuário ao acesso da informação ambiental e o gestor na tomada de decisão.

\section{Referências}

ASSOCIAÇÃO BRASILEIRA DE NORMAS TÉCNICAS (ABNT). NBR 12676: métodos para análise de documentos - determinação de seus assuntos e seleção de termos de indexação. Rio de Janeiro, 1992. 
BARBIERI, J. C. Gestão ambiental: conceitos, modelos e instrumentos. 3. ed. São Paulo: Saraiva, 2011.

BOTELHO, L. B. Organização e recuperação da informação em Ciências da Saúde: a elaboração de um microtesauro de Nutrição. 2008. 152f. Dissertação (Mestrado em Ciência da Informação) - Faculdade de Ciência da Informação, Universidade de Brasília. Brasília, 2008.

CABRÉ, M. T. La Terminologia hoy: concepciones, tendências y aplicaciones. Ciência da Informação, v. 24, n. 3, p.1-15, 1995.

CAMPELO, B. S. Teses e dissertações. In: CAMPELO, B. S.; CENDÓN, B. V.; KREMER, J. M. (Org.). Fontes de informação para pesquisadores e profissionais. Belo Horizonte: UFMG, 2000. p. 121-135.

CERVANTES, B. M. N. A construção de tesauros com a integração de procedimentos terminográficos. 2009. 209f. Tese (Doutorado em Ciência da Informação) - Faculdade de Filosofia e Ciências, Universidade Estadual Paulista. Marília, 2009.

CINTRA, A. M. M. et al. Para entender as linguagens documentárias. São Paulo: Polis, 2002.

CURRÁS, E. Tesauros: linguagens terminológicas. Brasília: IBICT, 1995.

DIAS, R. Gestão ambiental: responsabilidade social e sustentabilidade. São Paulo: Atlas, 2006.

DEREK, A. Diretrizes para o estabelecimento dos tesauros monolíngues. Brasília: IBICT, 1993.

DODEBEI, V. L. D. Tesauro: linguagem de representação da memória documentária. Rio de Janeiro: Interciência, 2002.

FINATTO, M. J. B.; KRIEGER, M. da G. Introdução à terminologia: teoria e prática. São Paulo: Contexto, 2004.

INSTITUTO BRASILEIRO DE INFORMAÇÃO EM CIÊNCIA E TECNOLOGIA (IBICT). Diretrizes para a elaboração de tesauros monolíngues. Brasília, 1984. [Projeto coordenado por Hagar Espanha Gomes].

JESUS, J. B. M. de. Tesauro: um instrumento de representação do conhecimento em sistemas de recuperação da informação. Recife: [s.n.], 2002.

LANCASTER, F. W. Construção e uso de tesauros: curso condensado. Brasília: IBICT, 1987.

LARA, M. L. G. de. Linguagem documentária e terminologia. Transinformação, Campinas, v. 16, n. 3, p. 231-240, set./dez. 2004.

LARA, M. L. G. de. Elementos de terminologia. São Paulo: ECA-USP, 2005. Disponível em: <http://infobservatorio.incubadora.fapesp.br/portal/int_terminol/bibliogra fia/elemterm2005.doc/view>. Acesso em: 5 maio 2014. 
LORENZON, E. Análise de domínio para avaliação de tesauros. 2011. Tese (Doutorado em Ciência da Informação) - Programa de Pós-graduação em Ciência da Informação, Universidade Estadual Paulista, São Paulo, 2011.

MACHADO, J. M. et al. O impacto ambiental como instrumento orientador na educação e na política ambiental. In: ENCONTRO NACIONAL DE ENGENHARIA DE PRODUÇÃO, 22., Curitiba, 2002. Anais ... Curitiba, 2002.

MACULAN, B. C.; LIMA, G. Â. B. de O. Relacionamentos em tesauros: o valor semântico dos verbos. Perspectivas em Ciência da Informação, v. 19, n. 4, p. 182-201, out./dez. 2014.

MAIA, P. C. C. Análise terminológica da produção científica dos Programas de Pós-Graduação (PPGs): a elaboração de um microtesauro sobre gestão ambiental. 2015. 180f. Dissertação (Mestrado em Gestão dos Recursos Naturais e Desenvolvimento Local) - Núcleo do Meio Ambiente, Universidade Federal do Pará, Belém, 2015.

MOMM, C. F. O conhecimento científico em turismo no Brasil: cursos de pós-graduação (Stricto Sensu) - período de 2000 a 2006. 2009. 131f. Dissertação (Mestrado em Ciências da Informação) - Universidade Federal de Santa Catarina, Florianópolis, 2009.

MOREIRA, A.; ALVARENGA, L.; OLIVEIRA, A. de P. O nível de conhecimento e os instrumentos de representação: tesauros e ontologias. DataGramaZero - Revista de Ciência da Informação, v. 5, n. 6, p. 1-25, dez. 2004.

PHILIPPI JR., A.; MAGLIO I. C. Política e gestão ambiental: conceitos e instrumentos. In: PHILIPPI JR., A.; PELICIONE, M. C. F. (Ed.) Educação ambiental e sustentabilidade. Barueri-SP: Manole, 2005. p. 217-256.

PHILIPPI JR., A.; ROMÉRO, M. de A.; BRUNA, G. C. Curso de gestão ambiental. Barueri: Manole, 2004. (Coleção Ambiental; 1).

PONTES, A. L. Terminologia científica: o que é e como se faz. Revista de Letras, v. 19, n. 2, p. 44-51, jan./fev. 1997.

QUINTAS, J. S. Introdução à gestão ambiental. Brasília: IBAMA, 2006.

SALES, R. de. Tesauros e ontologias sob a luz da teoria comunicativa da terminologia. 2008. 164f. Dissertação (Mestrado em Ciência da Informação) - Centro de Ciências da Educação, Universidade Federal de Santa Catarina, Florianópolis, 2008.

SALES, R.; CAFÉ, L. Diferenças entre tesauros e ontologias. Perspectivas em Ciência da Informação, v. 14, n. 1, p. 99-116, jan./abr. 2009.

SEIFFERT, M. E. B. Gestão ambiental: instrumentos, esferas de ação e educação ambiental. São Paulo: Atlas, 2011.

TINOCO, J. E. P.; KRAEMER, M. E. P. Contabilidade e gestão ambiental. 2.ed. São Paulo: Atlas, 2008. 
VAN DER LAAN, R. H. Tesauro e terminologia: uma inter-relação lógica. 2002.185f. Tese (Doutorado em Estudos da Linguagem) - Instituto de Letras, Universidade Federal do Rio Grande do Sul, Porto Alegre, 2002.

VARGAS, D. F. Estudo metodológico de elaboração de tesauros. 2010. 105f. Trabalho de Conclusão de Curso (Graduação em Biblioteconomia) Faculdade de Biblioteconomia e Comunicação, Universidade Federal do Rio Grande do Sul, Porto Alegre, 2010.

VASCONCELLOS SOBRINHO, M. Gestão ambiental. In: BOULLOSA, R. de F. (Org.). Dicionário para a formação em gestão social. Salvador: EUFBA, 2014. 